\title{
Environmental Control of ECS-Produced Retrograde Amnesia in Goldfish ${ }^{1}$
}

\author{
R. E. DAVIS AND M. S. HIRTZEL \\ Mental Health Research Institute and Department of Psychology, University of Michigan, \\ Ann Arbor, Michigan, U.S.A.
}

(Received 23 March 1970)

\begin{abstract}
DAvis, R. E. AND M. S. HiRTzel. Environmental control of ECS-produced retrograde amnesia in goldfish. PHYsIOL. BeHAV. $5(10), 1089-1092,1970$. The retrograde amnestic effect of ECS can be enhanced by exposing the goldfish to the intertrial environment for 25 min just prior to administration of the ECS. As the interval between training and the ECS is increased, the amnesia produced by the environment-ECS interaction takes longer to develop. The environment-dependent effects of ECS relate to those of other amnestic agents which have previously been described.
\end{abstract}

Amnesia Memory consolidation Shock avoidance Conditioning goldfish Electroconvulsive shock

OUR LABORATORY has reported that retrograde amnesia on a shock avoidance response can be induced a day after training and hours after memory has been consolidated [6]. It is sufficient merely to replace the fish in the intertrial environment (ITE) for $25 \mathrm{~min}$ just prior to administration of the agent. Stimuli in the ITE thus appears to reinstate the susceptibility of the memory to disruption. The reinstatement effect indicates that retrograde amnesia $[8,10,13]$ cannot be attributed exclusively to impairment of memory consolidation. Our experiments showed an interaction between the ITE and the effects of several chemical agents, namely intracranially administered potassium chloride $(\mathrm{KCl})$, puromycin, and acetoxycycloheximide, but not with electroconvulsive shock (ECS). Goldfish given the ITE-ECS treatment $24 \mathrm{hr}$ posttrial showed normal memory 6 days later which was the longest retention interval tested.

The present experiments were to investigate whether ECS interacts with an ITE exposure following posttrial intervals shorter than $24 \mathrm{hr}$. The results obtained with the other agents had indicated that the amnesia induced following the ITE period $24 \mathrm{hr}$ posttrial develops several times more slowly than amnesia induced immediately posttrial. This suggested that the reinstatement effect is time-dependent. Increased time in the home tank prior to the ITE exposure might result in decreasing reinstatement effects, such as slower development of amnesia, and eventually complete resistance to reinstatement. We looked for an ITE-ECS interaction at $4 \mathrm{hr}$ and $6 \mathrm{hr}$ posttrial, or shortly before and after the time at which memory was otherwise fixed to the effects of ECS.

\section{METHOD}

\section{Animals}

Goldfish $8.5-12.5 \mathrm{~g}$ were kept in large stock tanks for 5-14 days prior to training, and they were transferred to individual home tanks the day before an experiment. Fish were kept in continuous light, $19-20^{\circ} \mathrm{C}$, and they were not fed.

\section{Avoidance Training}

Shock avoidance was conditioned in individual 2-compartment shuttleboxes as previously described [6]. On Day 1 of an experiment, fish were moved in home tanks to the experimental room, placed in a shuttlebox for $5 \mathrm{~min}$ and then given 20 trials in 20 min. A trial started with the onset of a light stimulus outside the compartment containing the fish. After $15 \mathrm{sec}$ a repetitive electrical shock was presented in the light compartment for an additional $20 \mathrm{sec}$. A trial terminated after $35 \mathrm{sec}$ or when the fish crossed the barrier into the dark compartment. To swim over the barrier, fish had to deflect a transparent plastic gate which hung in the water above the barrier. Fish could avoid the shock by crossing the barrier during the first $15 \mathrm{sec}$ of a trial or escape from it by crossing during the last $20 \mathrm{sec}$. Movement of fish over the barrier was detected by a photodetector beam in each compartment. A PDP-8 computer controlled the presentation of light and shock stimuli, and recorded avoidances, failures to escape, and the number of shocks received for each fish. Goldfish were replaced in home tanks immediately following the trial 20 and returned to the storage room. Retention of avoidance conditioning was tested in a retraining session. Fish were placed in the shuttleboxes for 5 min then given 10 trials in $10 \mathrm{~min}$.

During the first $5 \mathrm{~min}$ of the training and retraining sessions, and during the $25 \mathrm{sec}$ intertrial interval, the shuttlebox was dark except for the thin, photoconductor light-beam in each compartment. This environment is referred to as the ITE. The prediction method [6] was used to evaluate retention. The number of avoidances fish achieved (A) in the 10 retraining trials was contrasted to the number which was predicted (P) on the basis of a multiple regression analysis of control

${ }^{1}$ Supported by NIMH research development award K2-MH-22, 183 (R.E.D.). 
data. Weekly prediction equations were obtained from about 100 independent controls trained over a period encompassing that week and the week before and after. The weekly regression was to compensate for seasonal changes in levels of responding.

The ECS consisted of an $8 \mathrm{~mA}, 100 \mathrm{msec}$ pulse of $60 \mathrm{cps}$ current. The shock was administered between two electrodes which were pressed on the cranium just posterior to the orbits. The sham ECS consisted of the same shock delivered across the caudle peduncle just posterior to the dorsal fin. Fish were lifted from the water with one hand, given the shock and immediately returned to the home tanks.

\section{RESULTS}

\section{Part 1. Posttrial ECS}

The instant effect of the ECS was a brief spasm of the body musculature of the fish. Following the shock fish showed episodes of quick vibratory movements for a few seconds to a minute or two. A fish might skitter wildly at the water surface for a few seconds or spin and bump into the tank bottom and walls several times before calming down. Some fish showed only a few twitches, following the initial spasm, and then remained still. The sham ECS produced a body jerk but no disequilibrium or convulsive movements.

The retrograde amnesic effects of ECS were first investigated in fish which were returned to home tanks immediately following training. The results are shown in Table 1 . Different fish received ECS at various times up to $6 \mathrm{hr}$ after the last training trial and were then retrained on Day 4 to test retention. Groups given ECS within $4 \mathrm{hr}$ after training showed memory losses on Day 4, while fish which received ECS at later times showed normal memory. Three additional groups were given ECS immediately following training and then retrained on Days 2, 3 and 5, to estimate the time-course of the development of the amnesia. The retention scores (A minus $P$ ) were -1.17 on Day $2,-2.45$ on Day 3 and -2.44 on Day 5. The marginal deficit (A vs. P) $(p<0.05)$ on Day 2 suggests that the amnesia was not yet fully developed by that time. But analysis of variance reveals that the retention interval effect is not significant $(F=1.59, d f=3 / 98)$ at the 0.05 level. The sham ECS had no effect on memory.

TABLE 1

ECS-Produced RA

\begin{tabular}{lcccc}
\hline Posttrial & $n$ & \multicolumn{3}{c}{ Day 4 Score } \\
\cline { 3 - 5 } ECS Time & & $\begin{array}{c}\text { Achieved } \\
\text { (A) }\end{array}$ & $\begin{array}{c}\text { Predicted } \\
\text { (P) }\end{array}$ & $\begin{array}{c}\text { Retention } \\
\text { (A-P) }\end{array}$ \\
\hline Immediate & 23 & 2.30 & 4.62 & $-2.32^{*}$ \\
$1 \mathrm{hr}$ & 27 & 2.74 & 4.43 & $-1.69^{*}$ \\
$3 \mathrm{hr}$ & 28 & 3.75 & 4.70 & $-0.95 \dagger$ \\
$4 \mathrm{hr}$ & 28 & 3.32 & 4.23 & $-0.94 \dagger$ \\
$5 \mathrm{hr}$ & 22 & 4.86 & 5.36 & -0.50 \\
$6 \mathrm{hr}$ & 24 & 4.62 & 4.86 & -0.24 \\
$24 \mathrm{hr}$ & 27 & 5.41 & 4.85 & +0.56 \\
Sham ECS & & & & \\
immediate & 27 & 5.04 & 4.48 & +0.56 \\
\hline
\end{tabular}

${ }^{*} p<0.01$ (achieved vs. predicted).

tp $<0.05$.

\section{Part 2. ITE-ECS Interaction}

The foregoing results indicated that when fish are immediately returned to home tanks following the $25 \mathrm{~min}$ training session memory is fixed to the disruptive effects of ECS in 4-5 hr. In the present experiment, fish were administered a 25 min exposure to the ITE just prior to ECS at 4 and $6 \mathrm{hr}$ posttrial and memory was tested on Day 4. Different fish were placed in the shuttleboxes in the ITE $3 \mathrm{hr}$ and $35 \mathrm{~min}$ and $5 \mathrm{hr}$ and $35 \mathrm{~min}$ following the training session. After $25 \mathrm{~min}$, the fish immediately received ECS (ITE-ECS group) or not (ITE group) and were returned to home tanks. The $4 \mathrm{hr}$ ITE-ECS group showed a deficit on Day 4, while the $6 \mathrm{hr}$ group showed normal retention (Table 2). The results in Table 2 showed that ECS $4 \mathrm{hr}$ posttrial produced some memory loss by Day 4 (deficit of -0.94 avoidances) but the ITE-ECS group showed a significantly larger loss. The $4 \mathrm{hr}$ ITE group showed normal memory. Thus the increased deficit of the ITE-ECS group indicates an enhancement of the amnestic effects of ECS by the exposure to the ITE.

TABLE 2

ITE-ECS INTERACTION

\begin{tabular}{|c|c|c|c|c|}
\hline \multirow{2}{*}{ Treatment } & \multirow{2}{*}{$n$} & \multicolumn{2}{|r|}{ Day 4 Score } & \multirow[b]{2}{*}{$\begin{array}{l}\text { Retention } \\
(\mathbf{A}-\mathbf{P})\end{array}$} \\
\hline & & $\begin{array}{l}\text { Achieved } \\
\text { (A) }\end{array}$ & $\begin{array}{l}\text { Predicted } \\
\text { (P) }\end{array}$ & \\
\hline \multicolumn{5}{|c|}{$4 \mathrm{hr}$ posttrial } \\
\hline ITE & 27 & 5.48 & 5.35 & +0.12 \\
\hline ECS & 28 & 3.32 & 4.23 & $-0.94 \dagger$ \\
\hline ITE-ECS & 28 & 2.64 & 5.16 & $-2.52^{*}$ \\
\hline \multicolumn{5}{|c|}{$6 \mathrm{hr}$ posttrial } \\
\hline ECS & 24 & 4.62 & 4.86 & -0.24 \\
\hline ITE-ECS & 28 & 4.82 & 5.44 & -0.61 \\
\hline
\end{tabular}

$$
{ }^{*} p<0.01 \text {. }
$$$$
\dagger p<0.05 \text {. }
$$

The ITE-ECS treatment at $6 \mathrm{hr}$ posttrial was further investigated to determine whether it results in amnesia which develops after Day 4. Two groups were given the $25 \mathrm{~min}$ ITE exposure ending at $6 \mathrm{hr}$ posttrial. One was returned immediately to home tanks (ITE group) and the other received ECS prior to being placed in home tanks (ITE-ECS group). Other fish were administered ECS $6 \mathrm{hr}$ posttrial without the ITE experience (ECS group). Retention was tested on Day 8. The ITE group showed normal memory (Table 3). The ECS and the ITE-ECS groups both showed memory losses but the ITE-ECS group showed the greater loss $(t$-test $; p<0.01)$.

\section{DISCUSSION}

The time-dependent effects of ECS shown in Table 1 confirm that ECS can produce RA on shock avoidance responding in goldfish [3]. One difference is that fixation time is twice that seen in the previous experiment, or 4-5 hr as contrasted to $1.5-2 \mathrm{hr}$. Conceivably changes in conditioning procedures between Tasks I and III [1] are responsible. Fixation time has been shown to vary with training 
TABLE 3

ITE-ECS INTERACTION

\begin{tabular}{lcccc}
\hline $\begin{array}{l}\text { Treatment } \\
\begin{array}{l}6 \mathrm{hr} \\
\text { posttrial }\end{array}\end{array}$ & $n$ & $\begin{array}{c}\text { Achieved } \\
\text { (A) }\end{array}$ & $\begin{array}{c}\text { Predicted } \\
\text { (P) }\end{array}$ & $\begin{array}{c}\text { Retention } \\
\text { (A-P) }\end{array}$ \\
\hline ITE & & & & \\
ECS & 26 & 4.73 & 5.27 & -0.54 \\
ITE-ECS & 28 & 4.39 & 5.69 & $-1.29 \dagger$ \\
& 19 & 2.53 & 5.91 & $-3.38^{*}$ \\
\hline
\end{tabular}

$* p<0.01$.

$\dagger p<0.05$.

procedures in rats [14]. Also the present fish were administered transcranial ECS instead of a whole-body shock, and the shock was shorter and more intense.

The memory loss produced by an immediate posttrial ECS was virtually fully developed in $24 \mathrm{hr}$, or by Day 2 . KClproduced amnesia similarly is developed in a matter of hours whereas puromycin results in a more gradual loss of memory over 2-3 days [6]. The effects of the ECS on memory after retention intervals of less than $24 \mathrm{hr}$ remains to be determined.

The results in Tables 2 and 3 support the previous impression that the environmental control of $\mathrm{RA}$ in goldfish is time-dependent [6]. As the interval in the home tank prior to presentation of the ITE-agent treatment is increased the rate of development of the resultant amnesia decreases. The gradient of the ITE-ECS interaction is steep as shown by the great difference in the rate of amnesia development obtained by delaying the ITE-ECS treatment $2 \mathrm{hr}$, from 4 to $6 \mathrm{hr}$ posttrial. We were surprised to find that an ECS $6 \mathrm{hr}$ posttrial results in a deficit 7 days later (Table 3). Memory fixation data is conventionally obtained by testing retention at a constant time after training; it is implicitly assumed that amnesia development is a constant. While the Day 4 data indicate that memory is fixed to the effects of ECS within $6 \mathrm{hr}$ after training (Table 1) the Day 8 data shows that memory fixation is not complete, some amnesia is produced, but the rate of development of the amnesia is slower.

The following comments on the ITE effect are intended to summarize some of the results obtained in goldfish experiments over the past few years. The first evidence of environmental control was that memory fixation seemed to be postponed during a $40 \mathrm{~min}$ training session [4]. This impression was confirmed in experiments which showed that fixation can be prolonged by keeping fish in the ITE following the last training trial $[4,5]$. We proposed that memory consolidation includes processes which can be controlled by manipulating stimuli in the external environment; the processes are slowed by continued exposure to the ITE and triggered, or accelerated by removal of fish from the training environment. This interpretation was weakened by the finding of the reinstatement effect of the ITE. An ITE-agent interaction does not require a continuous posttrial exposure to the ITE. It is thus unnecessary to postulate that memory consolidation is delayed or prolonged by stimuli in the training environment. Reinstatement may represent a resetting of certain phases of memory storage which are more quickly completed when fish are in the home tank than in the training environment. Irwin et al. [9] have suggested that following memory consolidation there is a period of integrative and elaborative processes which though vulnerable to ECS disruption can be reinstated in the presence of stimuli from the original training situation. The posttraining attenuation of the ITE effect could indicate that older memory is more resistant to reinstatement. The exact processes that are reset, and the extent of the resetting may vary over time following learning and with the stimuli used to obtain reinstatement. Our limited results do not preclude the possibility that some reinstatement can always be obtained, if not with stimuli in the ITE perhaps with some other stimulus such as a reminder shock administered in the shuttlebox. Different agents, such as ECS and puromycin, may disrupt different memory processes. Such differences might explain some of the variation in the ITE effect observed with different agents.

Another interpretation of the reinstatement effect which has greater appeal to us is that amnesic agents have stimulus effects which become associated with the training environment, or with physiological states induced by the environment, with the result that retrieval of the avoidance response is impaired The time-dependence of the ITE effect may reflect a weakening of the fish's response to stimuli in the ITE as reminders of the training situation. The various agents may, for example, produce a generalized emotional response to the training environment which competes with the avoidance response. The relation between the ITE effect in goldfish and the reported training stimulus-ECS interactions in rats $[2,7,8,11,12,15]$ is not clear. An important question to be answered is whether environmental control varies with different external stimuli. Possibly reinstatement can be obtained with stimuli not directly related to the training environment. Reinstatement may depend more upon evocation of specific emotional states than on discriminative recognition of stimuli from a particular behavioral situation.

\section{REFERENCES}

1. Agranoff, B. W. and R. E. Davis. The use of fishes in studies on memory formation. In: The Nervous System and Fish Behavior, edited by D. Ingle. Chicago, Illinois, University of Chicago Press, 193-201, 1968.

2. Banker, G., E. Hunt and R. Pagano. Evidence supporting the memory disruption hypothesis of electroconvulsive shock action. Physiol. Behav. 4: 895-899, 1969

3. Davis, R. E., P. J. Bright and B. W. Agranoff. Effect of ECS and puromycin on memory in fish. J. comp. physiol. Psychol. 60: 162-166, 1965.

4. Davis, R. E. and B. W. Agranoff. Stages of memory formation in goldfish: Evidence for an environmental trigger, Proc. nain. Acad. Sci. U.S.A. 55: 555-559, 1966.
5. Davis, R. E. Environmental control of memory fixation in goldfish. J. comp. physiol. Psychol. 65: 72-78, 1968.

6. Davis, R. E. and P. D. Klinger. Environmental control of amnesic effects of various agents in goldfish. Physiol. Behav. 4: 269-271, 1969.

7. Dawson, R. G. and J. L. McGaugh. Electroconvulsive shock effects on a reactivated memory trace: Further examination. Science 166: 525-527, 1969.

8. Lewis, D. T. Sources of experimental amnesia. Psychol. Rev. 76: 461-472, 1969.

9. Irwin, S., A. Banuazizi, S. Kalsner and A. Curtis. One trial learning in the mouse. 1. Its characteristics and modification by experimental-seasonal variables. Psychopharmacology 12: 286-302, 1968. 
10. McGaugh, J. L. Time dependent processes in memory storage Science 153: 1351-1358, 1966.

11. Robbins, M. J. and D. R. Meyer. Motivational control of retrograde amnesia. J. exp. Psychol, in press, 1970.

12. Schneider, A. M., A. Malter and C. Advokat. Pretreatment effects of a single ECS and footshock plus ECS on step-down latencies of trained and untrained rats. J. comp. physiol. Psychol. 68: $627-630,1969$.
13. Spevack, A. A. and M. D. Suboskı. Retrograde effects of electroconvulsive shock on learned responses. Psychol. Bull. 72: 66-76, 1969.

14. Thompson, R. The effects of degree of learning and problem difficulty on perseveration. J. exp. Psychol. 55: 496-500, 1958.

15. Walker, E. L. In: The Organization of Recall, edited by D. P. Kımble. New York Academy of Sciences, 186-233, 1967. 